\title{
THE STUDY OF GROWTH KINETICS OF BACILLUS SUBTILIS BMT4I (MTCC 9447) USING MOBIL OIL AS THE SOLE CARBON AND ENERGY SOURCE
}

\author{
Madhuri Kaushish Lily, Kamlesh Kumar Bhatt, Lalit Kumar and Koushalya Dangwal* \\ Department of Science, Modern Institute of Technology (MIT), Dhalwala, Rishikesh-249201, \\ Uttarakhand, India.
}

Corresponding author E-mail: kdangwal1@yahoo.co.in

Received: 20.04.2019; Revised: 26.06.2019; Accepted: 10.08.2019

CSociety for Himalayan Action Research and Development

\begin{abstract}
The present study demonstrated the growth kinetics of a potent high molecular weight polycyclic aromatic hydrocarbon (HMW-PAH) degrader Bacillus subtilis BMT4i (MTCC 9447) using mobil oil or engine oil as the sole carbon and energy source. The study was performed to demonstrate the variations in morphology and growth kinetics in benzo-a-pyrene $(\mathrm{BaP})$ degrading BMT4i due to the mobil oil induced stress conditions. The morphological variations were evaluated using Gram staining and spore staining (Schaeffer-Fulton method) followed by assessment of viability and growth using colony forming units (CFU)/ml method by means of growing Bacillus subtilis BMT4i in basal salt medium (BSM) with mobil oil (2\%: BSMM) as sole carbon and energy source at different time intervals. The findings represented that mobil oil has noticeable effect on the shape and size of BMT4i cells. After $24 \mathrm{~h}$ of exposure to mobil oil, maximum BMT4i cells entered in to endospore development and several exospores were released after $24 \mathrm{~h}$. The growth kinetics depicted an exponential increase in BMT4i cells in BSMM with increase in incubation time up to 3 days accomplishing maxima of $2.1 \times 10^{19}$ demonstrating approx. $2 \times 10^{11}$-fold enhancements in cell number and afterwards cell number declined. Increase in CFU number (approx. $2 \times 10^{11}$ fold) was directly linked with the BMT4i potential to use mobil oil as the sole carbon and energy source leading to elevation in cell number within just 3 days. Thus, it could be concluded that Bacillus subtilis BMT4i (MTCC 9447) is very competent in using mobil oil as the sole source of carbon and energy and hence it could be employed for bioremediation of mobil oil and PAH contaminated sites.
\end{abstract}

Keywords: Bacillus subtilis BMT4i (MTCC 9447), Benzo-a-pyrene (BaP), Bioremediation, Degradation, Mobil oil.

\section{Introduction}

Mobil oil or Engine oil is the oil which is used for lubrication of various internal combustion engines and it is one of the several refined products or cuts of crude oil (Bagherzadeh-Namazi et al., 2008). It is composed of a mixture of base polycyclic aromatic hydrocarbons (PAHs) having saturated and unsaturated long-chain with $\mathrm{C} 16-\mathrm{C} 36$ carbon length, cyclic alkanes and additives such as anticorrosive, antiwearing and antitearing agents (Koma et al., 2003). The main function is to lubricate moving parts; it also cleans, inhibits corrosion, improves sealing, and cools the engine by carrying heat away from the moving parts (Hagwell et al., 1992). The most important characteristic of the lubricating oil for automotive use is its viscosity (Tripathi and Vinu, 2015). The illegal dumping of used engine oil is dangerous to the environment and constitutes a serious threat to humans, animals, and vegetation (Bhattacharya and Biswas, 2014). After sometime of usage in engine operation, the lubricating oil become enriched with more metals and heavy polycyclic aromatic hydrocarbons (PAHs) that could pose chronic hazard including mutagenicity and carcinogenicity (Wong and Wang, 2001; Dominguez-Rusado et al., 2003; Adelowo et al., 2006; Lu S-T et al., 2008). 
Several mechanical methods which are employed to reduce hydrocarbon pollution are often expensive and time-consuming. On the other hand, Bioremediation especially microbial degradation remains one of the most effective ways to reclaim soils and aquifers polluted with petroleum hydrocarbons (Akio et al., 2006). Success of bioremediation would depend on the availability of petrogenic organisms with capacity to degrade the broad array of components in the contaminant. There are few reports of degraders of engine oil spanning bacterial strains of genera such as Achromobacter, Bacillus, Brevundimonas, Enterobacter, Escherichia, Gordonia, Mycobacterium, Nocardia, Pseudomonas, Rhodococcus, Serratia and Staphylococcus among others (Amund and Adebiyi, 1991; Jirasripongpun K, 2002; Koma et al., 2003; Adelowo et al., 2006; Mandri and Lin ,2007; Wang et al., 2007; Basuki et al., 2011; Pathak and Jaroli, 2012; Jayashree et al., 2012; Obayori et al., 2014; Basuki W, 2017; Parikh et al., 2018). Also, there had been some reports specifically detailing degradation of used engine oil by bacteria (Bagherzadeh-Namazi et al., 2008; Basuki et al., 2011). However, there is growing research on the isolation of microorganisms which are capable of degrading the major components of engine oils; in addition showing versatility for other more recalcitrant hydrocarbons, since these pollutants are mostly found together in the same environmental compartments. Here, we report the degradation of mobil or engine oil by novel bacterial strain Bacillus subtilis BMT4i (MTCC 9447), a bacterium previously reported as potent degrader of high molecular PAHs (HMW-PAHs) including benzo-a-pyrene $(\mathrm{BaP})$, as sole source of carbon and energy (Lily et al., 2009). It is of great significance to ensure the ability of BMT4i to use fuel such as mobil oil as the sole carbon and energy source and hence the degradation of harmful PAHs present in it. Therefore, with the aim of understanding and revealing the morphological and growth variations in BMT4i imposed by the stress environment of mobil oil, the present study is focused on studying the growth kinetics of Bacillus subtilis BMT4i
(MTCC 9447) using mobil oil as the sole carbon and energy source.

\section{Materials and Methods}

Chemicals and reagents: Tryptone, peptone, beef extracts, bacto-agar, yeast extract, dextrose and staining reagents used in the present study were purchased from HiMedia Laboratories (Mumbai, India). General chemicals, including constituents of basal salt mineral medium (BSM) of analytical grade were purchased from Glaxo (Mumbai, India) and Merck (Mumbai, India).

\section{Growth Kinetics of BMT4i in Mobil oil and Glucose media}

To determine the potential of Bacillus subtilis BMT4i to use mobil oil as the sole carbon and energy source, the growth kinetics of BMT4i in BSMM ( $2 \%$ mobil oil) was studied. Gram staining and spore staining (Schaeffer-Fulton method) of BMT4i cultures at various time durations were performed in order to study the morphological variations. In addition, the viability of BMT4i was also checked by CFU method as mentioned previously (Lily et al., 2009).

All the experiments were performed in triplicates. For growth kinetics assessment of BMT4i, $250 \mathrm{ml}$ of nutrient broth was inoculated with a single colony of BMT4i and incubated at $37^{\circ} \mathrm{C}$ under shaking at $120-150 \mathrm{rpm}$ until the $\mathrm{A}_{600}$ reaches to

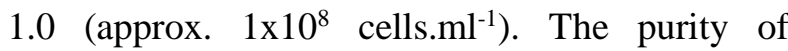
culture and absence of spores were confirmed by the Gram Staining and spore staining of the culture respectively. Afterwards, the BMT4i culture was spin at $8000 \mathrm{rpm}$ for 10 minutes and rinsed thrice with BSM in order to remove traces of nutrient broth followed by suspension of pellet in $25 \mathrm{ml}$ of BSM and adjusting the cell number to $10^{8}$ cells.ml ${ }^{-1}$ in BSM.

For growth kinetics studies, the test and control flasks were set up. In the test flask, $2.0 \mathrm{ml}$ of 
BMT4i-BSM suspension culture $\left(2 \times 10^{8}\right.$ cells. $\left.\mathrm{ml}^{-1}\right)$ was inoculated in $250 \mathrm{ml}$ flask containing $100 \mathrm{ml}$ BSMM. For the evaluation of BMT4i growth in mobil oil, $2.0 \mathrm{ml}$ culture was inoculated in separate $250 \mathrm{ml}$ flask containing $100 \mathrm{ml}$ of BSM with $2.0 \%$ glucose (BSMG) and incubated in shaker $(150 \mathrm{rpm})$ at $37^{\circ} \mathrm{C}$ for different time durations alongside respective controls lacking BMT 4i. At different time points $(0,1,2,3,7,14$, $21,28,35,42$ days $)$, BMT4i culture $(1.0 \mathrm{ml})$ was removed from every test flasks of BSMM and BSMG cultures. Firstly, the morphology of BMT4i cells was assessed using Gram staining and presence of spores in the culture was evaluated by spore staining followed by determination of CFU. $\mathrm{ml}^{-1}$ of BMT4i to determine the viability and growth of BMT4i in BSMM and BSMG media. For that, $100 \mu 1$ cultures were withdrawn from every test and control flasks and diluted up to $10^{-14}$ followed by spread plating over BSMG agar (1.5\%) plates and incubation at $37^{\circ} \mathrm{C}$. After $24 \mathrm{~h}$ of incubation, the colonies were counted and $\mathrm{CFU} / \mathrm{ml}$ was calculated. The growth curve of BMT4i was prepared by plotting $\log _{10} \mathrm{CFU} \cdot \mathrm{ml}^{-1}$ of BMT4i against incubation time.

\section{Results and Discussion}

\section{Growth Kinetics of Bacillus subtilis BMT 4i (MTCC 9447) in BSMM}

The current study was aimed to study the growth kinetics of a novel bacterial strain Bacillus subtilis BMT4i (MTCC 9447) using mobil oil as the sole carbon and energy source and to recognize and reveal the variations in the morphology and growth in BMT4i imposed by the stress induced by mobil oil. For that, the BMT4i was grown in media containing mobil oil for various time intervals. The BMT4i morphological characteristics were determined through Gram and spore staining. Thereafter, BMT4i viability was assessed using CFU method. The Gram staining of BMT4i culture grown in BSMM revealed that mobil oil imparted a noticeable effect on the shape and size of BMT4i cells. After $24 \mathrm{~h}$, there was a reduction in BMT4i rod size and width; however
BMT4i shape remained constant until 7 days. The pattern of BMT4i chain arrangement which was obvious at 0 day vanished after $24 \mathrm{~h}$. Subsequently, round pleomorphic BMT4i cells were observed rather than rods showing abundance till 28 days (Fig. 1). The spore staining of BMT4i culture in BSMM media demonstrated that endospore formation in maximum BMT4i cells in mobil oil exposure of $24 \mathrm{~h}$. Some exospores were also released after $24 \mathrm{~h}$. There was an enormous increase in spores up to 21 days, thereafter their number remained constant (Fig. 1).

This study is the first report representing the mobil oil growth medium induced morphological alteration of any bacterial species. The alteration in the rod width and size besides spore induction in the mobil oil media is fairly reasonable given that mobil oil is not the standard source of carbon source and BMT4i has to provoke mobil oil degradation pathway for adaptation to mobil oil stress environment.

Formerly, it has been shown that under nutritional deprivation, microbes reside in resting state remaining inactive for a fairly long period of time (Errington J, 2003). A wide range of bacteria employ specialized differentiated cell types including spores as a means to withstand starvation and hence survive under harsh environment. Bacillus subtilis attain a robust resting state, known as endospore which can remain dormant for several years. It is well recognized that formation of bacterial endospore is an energy demanding and prolong process.

The growth kinetics demonstrated the capability of BMT4i to use mobil oil for growth as depicted in graph of $\log _{10}$ of CFU/ml (cell number) verses incubation time, with an initial $8.326 \log _{10}$ CFU.ml ${ }^{-1}\left(2.12 \times 10^{8}\right)$, the BMT4i cell number increased exponentially up to 3 days, slightly declined and became stationary up to 21 days (Fig. 2). Afterwards, the cell number declined considerably. The CFU. $\mathrm{ml}^{-1}$ increased linearly following $24 \mathrm{~h}\left(13.579 \log _{10}\right.$ CFU.ml $\left.{ }^{-1}\right)$ reaching 
maxima of $19.322 \log _{10} \mathrm{CFU}_{\mathrm{m}} \mathrm{ml}^{-1}\left(2.1 \times 10^{19}\right)$ after $72 \mathrm{~h}$ achieving approx. $2 \times 10^{11}$-fold enhancement in growth. Afterwards, there was a slow reduction in CFU/ml reaching $17.9063 \log _{10}$ CFU.ml ${ }^{-1}$ (8.06 $\mathrm{x} 10^{17}$ ) following $7^{\text {th }}$ day which remained constant until 21 day, thereafter the viability of BMT4i cells declined drastically. The enhancement of approx. $2 \times 10^{11}$ fold CFU could be straightway linked with Bacillus subtilis BMT4i capability to use mobil oil as sole carbon and energy source which has resulted in exponential rise in cell number within merely 3 days. The BMT4i capability to use mobil oil as carbon and energy source is not unexpected given that BMT4i has been isolated from PAH contaminated soil and has intrinsic ability to grow on hydrocarbons (Lily et al., 2009). Nevertheless, it is unpredicted that regardless of gross morphological changes and early sporulation stimulation; BMT4i reproduction continues achieving maximum cell number. The explanation for which is indecisive. The maintenance of elevated growth in stationary phase might be explained by the fact that growth of bacterial and PAH utilization as a sole carbon and energy source in the broth culture which moreover depends upon the rate of aqueous dissolution of PAH (Johnsen et al., 2005). As soon as the PAH utilization by the growing population surpass the PAH aqueous dissolution rate, the soluble PAH concentration plunges and exponential growth stops, although culture media contains adequate quantity of PAH which is unavailable owing to low aqueous dissolution rate (Johnsen et al., 2005). In the present study, it is likely that metabolic requirement of remarkably high BMT4i cell number in peak growth may possibly be unfulfilled by the aqueous soluble fraction of mobil oil and consequently the cell number declined.

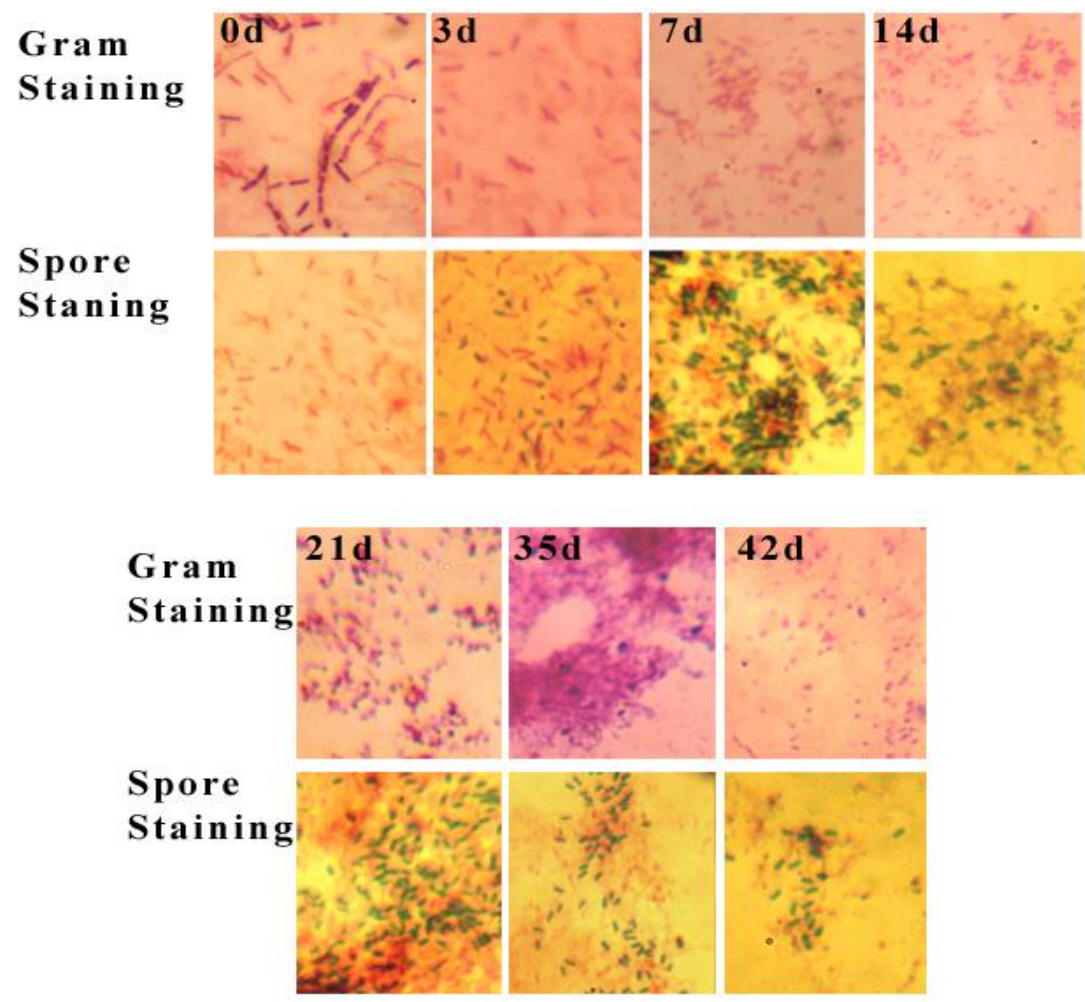

Fig. 1: Micrograph Showing Gram Staining and Spore Staining of Bacillus subtilis BMT4i Grown for 0, $3,7,14,21,35$ and 42 days in BSMM (BSM with 2\% mobil oil) Medium. (Magnification $1000 \mathrm{X}$ ) 


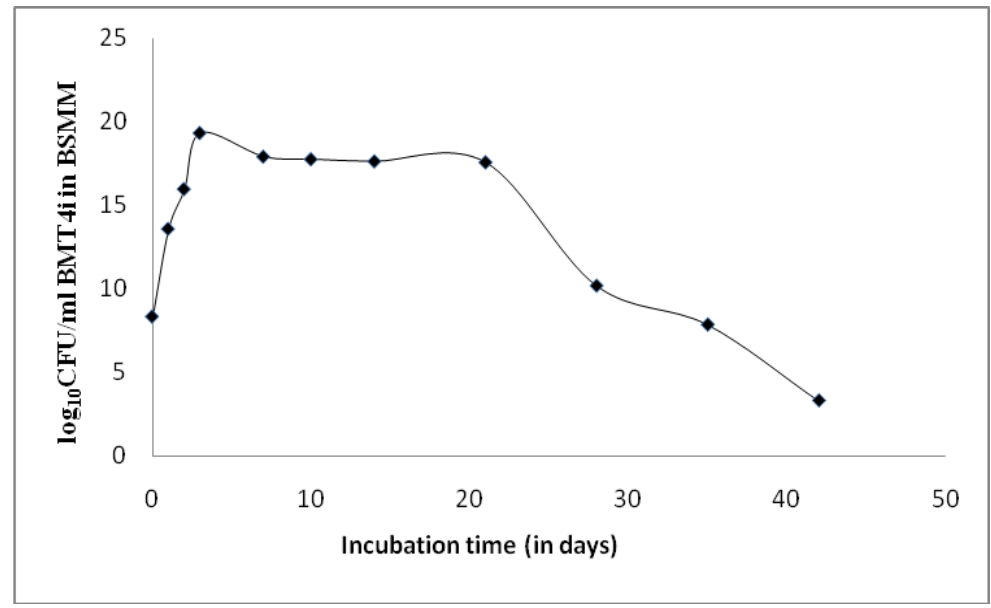

Fig. 2: Growth $\left(\log _{10}\right.$ CFU.ml ${ }^{-1}$ ) of Bacillus subtilis BMT4i (MTCC 9447) in BSMM (BSM with 2\% mobil oil) for Various Incubation Duration (days). Each Point Represents the Average Value Obtained with Three Independent Experiments.

\section{Growth Kinetics of Bacillus subtilis BMT 4i (MTCC 9447) in BSMG}

To compare BMT4i growth kinetics in BSMM to that in BSMG containing glucose as standard carbon source, Bacillus subtilis BMT4i was grown in BSMG broth for various time intervals followed by its morphological assessment employing Gram and spore staining besides estimating viability using $\mathrm{CFU} / \mathrm{ml}$ method. The Gram staining showed insignificant effect on BMT4i shape and size up to 10 days. Nevertheless, following 10 day, BMT4i cells showed loss of chain arrangement. Subsequently, after 21 days, the BMT4i long rod shaped cells were replaced by small sized cells (Fig. 3).

Afterwards, there was decline in the cell number and maximum cells morphology became distorted by 42 days. The spore staining of BMT4i grown in BSMG confirmed lack of BMT4i spores up to 7 days. On $10^{\text {th }}$ day, a small number of exospores were observed on spore staining of BMT4i-BSMG culture. Thereafter, spore number enhanced and became enormous by 42 days.

The findings evidently demonstrated usual morphological features as thick rods presenting chain arrangement and absence of sporulation up to 7 days in the BSMG. It is not startling; in view of the fact that glucose is a readily utilizable source of carbon therefore, cells remained healthy for much time in its presence. Later on after 7 days of decent growth, owing to depletion of glucose as carbon source, stress environment was imposed on BMT4i cells which resulted in induction of spore formation which became apparent by release of a small number of spores by 10 days.

The growth kinetics experiment in BSMG demonstrated that the cell number of BMT4i increased exponentially with increase in incubation duration up to 3 day and there after it became almost static up to 10 days and later on it started declining slowly (Fig. 4). The initial $1.2 \mathrm{x}$ $10^{8}$ BMT4i cells (8.0792 $\log _{10}$ of CFU.ml ${ }^{-1}$ ) inoculated on 0 day started increasing linearly after $24 \mathrm{~h}$ (11.0170 $\log _{10}$ CFU.ml $\left.{ }^{-1}\right)$ attaining maximum $19.0212 \log _{10} \mathrm{CFU}_{\mathrm{ml}}{ }^{-1}\left(1.05 \times 10^{19}\right)$ on $3^{\text {rd }}$ day of incubation which is almost equivalent to $1 \times 10^{11}$-fold enhancement in cell number. Thereafter, the cell number remained almost static up to $10^{\text {th }}$ day $\left(19.7324 \log _{10}\right.$ CFU.ml $\left.{ }^{-1}\right)$ followed by decline in viability. 


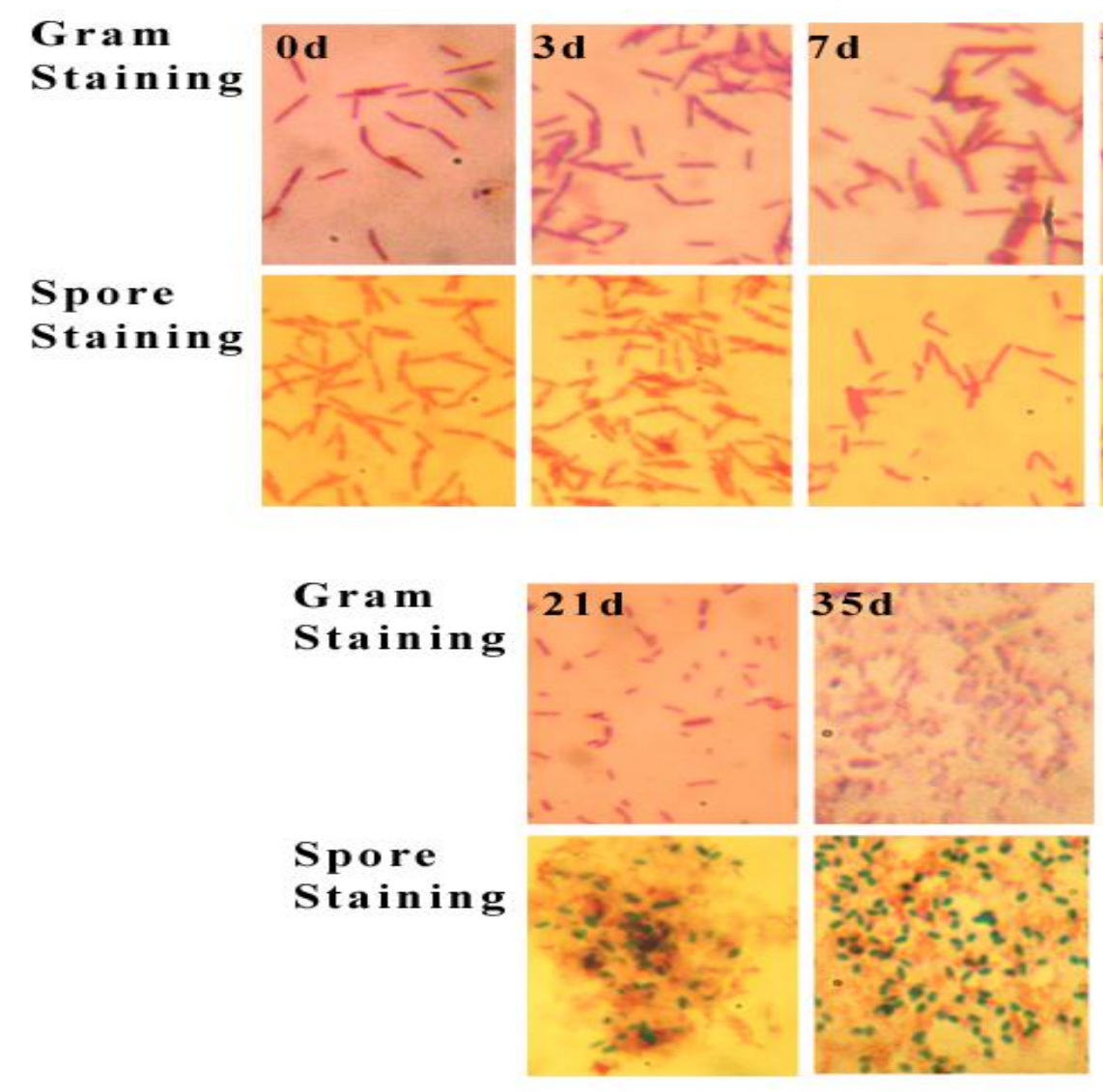

Fig. 3: Micrograph Showing Gram Staining and Spore Staining of Bacillus subtilis BMT4i Grown for 0, 3, 7, 10, 21, and 35 days in BSMG (BSM with 2\% Glucose) Medium. (Magnification 1000 X)

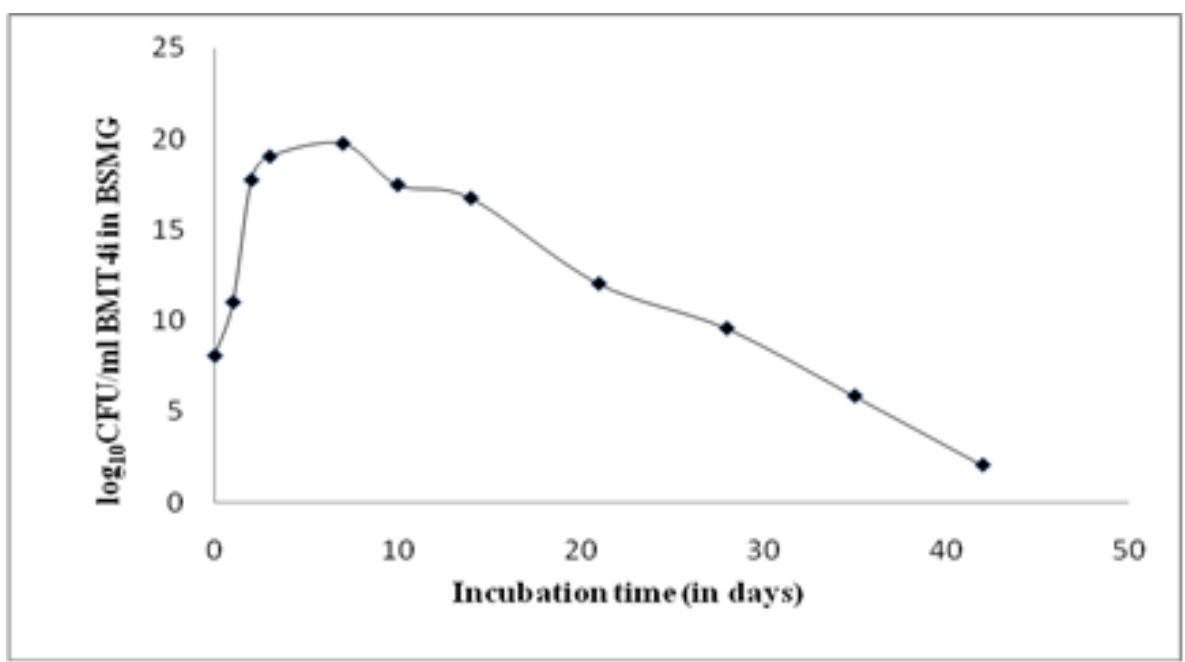

Fig. 4: Growth (log10 CFU.ml-1) of Bacillus subtilis BMT4i (MTCC 9447) in BSMG (BSM with 2\% Glucose) for Various Incubation Duration (days). Each Point Represents the Average Value Obtained with Three Independent Experiments. 


\section{Conclusion}

The present study is the first report evaluating the impact of mobil oil on the morphology and growth kinetics of bacteria (Bacillus subtilis BMT4i). The study clearly demonstrated mobil oil induced morphological variations and early sporulation in BMT4i in contrast to that of glucose.

\section{Acknowledgement}

This work was supported by the Modern Institute of Technology, Rishikesh, Uttarakhand, India that is gratefully acknowledged.

\section{References}

Adelowo, OO, Alagbe, SO and Ayandele, AA (2006) Time-dependent stability of used engine oil degradation by cultures of Pseudomonas fragi and Achromobacter aerogenes. Afr. J. Biotechnol. 5: 3476-2479.

Akio, U, Mohammad, H, Isao, Y and Hidetoshi, O (2006) Verification of Degradation of $n$ alkane in Diesel Oil by Pseudomonas aeruginosa Strain WatG in Soil Microcosms. Curr. Microbiol. 52: 82-185.

Amund, OO and Adebiyi, AG (1991) Effect of viscosity on the biodegradability of automotive lubricating oils. Tribol. Int. 24: 235-237.

Bagherzadeh-Namazi, A, Shojaosadati, SA and Hashemi-Najafabadi, S (2008) Biodegradation of used engine oil using mixed and isolated cultures. Int. J. Environ. Res. 2(4): 431-440.

Basuki, W (2017) Biodegradation of Used Synthetic Lubricating Oil by Brevundimonas diminuta AKL 1.6. Makara J. Sci. 21 (3): 136142.

Basuki, W, Syahputra, K, Suryani, AT and Pradipta, I (2011) Biodegradation of used engine oil. Indones. J. Biotechnol. 16: 132138.

Bhattacharya, M and Biswas, D (2014) Enhancement of waste engine oil biodegradation by optimization of media using factorial design study. Indian $J$. Biotechnol. 13: 293-300.

Dominguez-Rusado, E and Pitchel, J (2003) Chemical characterization of fresh and weathered motor oil via GC/MS, NMR and FITR Techniques. Proc. Indiana. Acad. Sci. 112: 109-116.

Errington, J. (2003). Regulation of endospore formation in Bacillus subtilis. Nat.Rev. Microbiol. 1: 117-126.

Hagwell, IS, Delfino, LM and Rao, JJ (1992) Partitioning of polycyclic aromatic hydrocarbons from oil into water. Environ. Sci. Technol. 26: 2104-2110.

Jayashree, R, Evany, NS, Rajesh, PP and Krishnaraju, M. (2012). Biodegradation capability of bacterial species isolated from oil contaminated soils. J. Acad. Ind. Res. 1: 140-143.

Jirasripongpun, K (2002) The characterization of oil-degrading microorganisms from lubricating oil contaminated (scale) soil. Lett. App. Microbiol. 35: 296-300.

Johnsen, AR, Wick, LY and Harms, H (2005) Principles of microbial PAH-degradation in soil, Environ. Poll.133: 71-84.

Koma, D, Sakashita, Y, Kubota, K, Fujii, Y and Hasumi, F et al. (2003) Degradation of car engine base oil by Rhodococcus sp. NDKK48 and Gordonia sp. NDKY76A. Biosci. Biotechnol. Biochem. 67: 1590-1593.

Lily, MK, Bahuguna, A, Dangwal, K and Garg V (2009) Degradation of Benzo[a]pyrene by a novel strain Bacillus subtilis BMT4i (MTCC 9447). Braz. J. Microbiol. 40 (4): 884-892.

Lu, S-T and Isaac, K (2008) Characterization of motor lubricating oils and their oil water partition. Environ. Forensics 9: 295-309.

Mandri, T and Lin, J (2007) Isolation and characterization of engine oil degrading indigenous microorganisms in KwazuluNatal, South Africa. Afr. J. Biotechnol. 6: 2327.

Obayori, OS, Salam, LB and Ogunwumi, OS (2014) Biodegradation of fresh and used engine oils by Pseudomonas aeruginosa LP5. J. Bioremed. Biodegrad. 5: 213, 
Parikh, DR, Tipre, DR, Nayak, NS and Dave, SR (2018) Degradation of discarded used engine Oil by Pseudomonas aeruginosa DP-1 and its optimization. Int. J. Curr. Microbiol. Appl. $\begin{array}{llll}\text { Sci. } & 7 & \text { (04): } 224-2229 \text {, }\end{array}$ doi:0.20546/ijcmas.2018.704.253

Pathak, H and Jaroli, BP (2012) Biochemical characterisation of $4 \mathrm{t}$ engine oil degrading microorganism isolated from polluted soil with petroleum hydrocarbons. Ind. J. Fundam. Appl. Life Sci. 2: 300-305.

Tripathi, AK and Vinu, R (2015) Characterization of thermal stability of synthetic and semisynthetic engine oils. Lubricants 3: 54-79,

Wang, L, Wang, LF-T and Liu, H (2007) Treatment of engine oil polluted waste water with mixed bacterial floral and kinetics of biodegradation. J. Chongqing Univ. 6: 238241.

Wong, PK and Wang, J (2001) The accumulation of polycyclic aromatic hydrocarbons in lubricating oil over time-a comparison of supercritical fluid and liquid-liquid extraction methods. Environ. Pollut. 112: 407-415. 